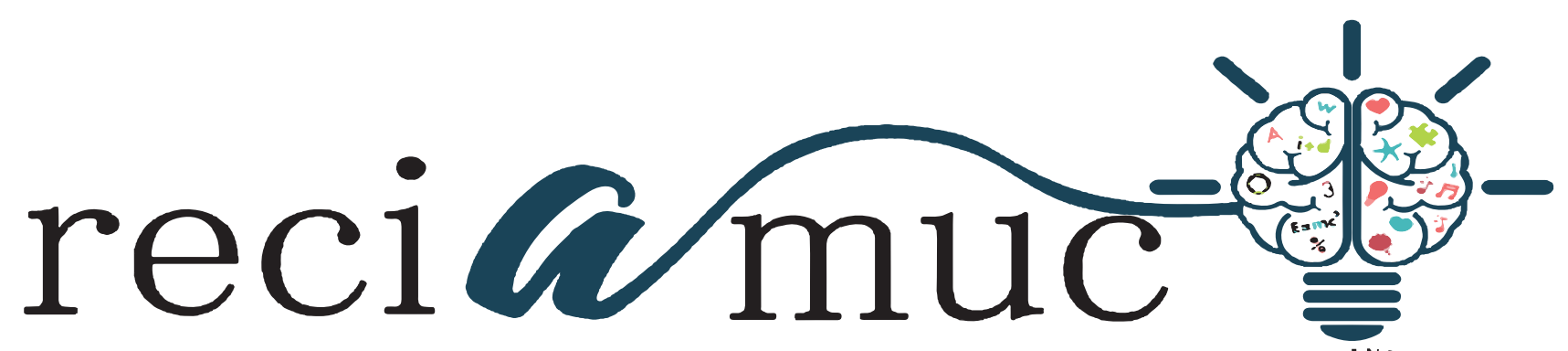

DOl: $10.26820 /$ reciamuc/4.(3).julio.2020.375-388

URL: https://reciamuc.com/index.php/RECIAMUC/article/view/536

EDITORIAL: Saberes del Conocimiento

REVISTA: RECIAMUC

ISSN: 2588-0748

TIPO DE INVESTIGACIÓN: Artículo de Revisión

CÓDIGO UNESCO: 3213.13 Estomatología

PAGINAS: $375-388$

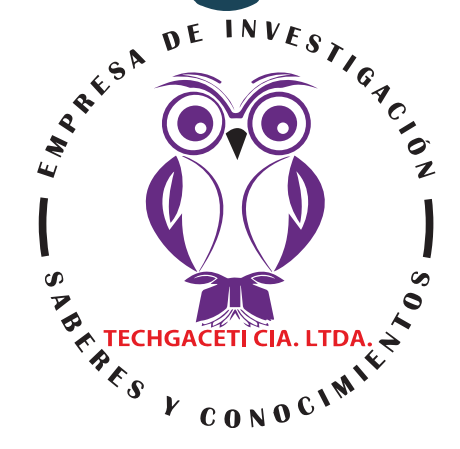

\title{
Revisión bibliográfica del calen/ZO como material obturador en pulpectomías
}

Calen/ZO as obturation material in pulpectomies: a bibliographic review

Calen/ZO como material de obturação em pulpectomias: umâ revisão bibliográfica

Odont. Esp. Tannya Lucila Valarezo Bravo'; Est. Mayra Juliana Torres Villalta²

RECIBIDO: 20/05/2020 ACEPTADO: 19/07/2020 PUBLICADO: 05/10/2020

1. Especialista en Odontopediatría; Odontóloga; Docente de la Universidad Nacional de Loja; Loja, Ecuador; tannya.valarezo@unl.edu.ec; iD https://orcid.org/0000-0002-3906-1850

2. Estudiante de la Carrera de Odontología; Universidad Nacional de Loja; Loja, Ecuador; mjtorresv@unl.edu.ec; (DD https:// orcid.org/0000-0003-3861-8810

CORRESPONDENCIA

Mayra Juliana Torres Villalta

mjtorresv@unl.edu.ec

\section{Loja, Ecuador}

(C) RECIAMUC; Editorial Saberes del Conocimiento, 2020 


\section{RESUMEN}

Los materiales de obturación para pulpectomías, deben cumplir ciertas propiedades que ayudan a mantener los dientes primarios en la cavidad bucal hasta su proceso de exfoliación, en este artículo se habla sobre la efectividad del calen más óxido de zinc como material de obturación en pulpectomías en dientes deciduos, se realizó una revisión bibliográfica con publicaciones de los últimos 5 años, mediante búsquedas en las bases de datos: Sciencedirect, Google Scholar y Medline tomando en cuenta dos variables: la efectividad y los efectos adversos del Calen. Finalmente, el Calen/OZ ha tenido buena acogida en el mercado odontológico por su biocompatibilidad con el tejido dentario; pero sin duda, aún no existe un material ideal al 100\%, por lo que se registra algunas desventajas leves del material.

Palabras clave: Calen/ZO, pulpectomía, necrosis, dientes temporales, técnica de obturación, material de obturación.

\section{ABSTRACT}

The obturation materials for pulpectomies must meet certain properties that help to maintain the primary teeth in the oral cavity until their exfoliation process, this article talks about the effectiveness of calcium plus zinc oxide as a filling material in pulpectomies on teeth deciduous, a bibliographic review was carried out with publications from the last 5 years, by searching the databases: ScienceDirect, Google Scholar and Medline taking into account two variables: the effectiveness and adverse effects of Calen. Finally, Calen/ZO has been well received in the dental market due to its biocompatibility with dental tissue; but there is certainly no $100 \%$ ideal material yet, so there are some slight disadvantages of the material.

Keywords: Calen/ZO, pulpectomy, necrosis, temporary teeth, filling technique, filling material.

\section{RESUMO}

Os materiais de obturação para pulpectomias devem atender a certas propriedades que auxiliem na manutenção dos dentes decíduos na cavidade oral até seu processo de esfoliação, este artigo fala sobre a eficácia do cálcio mais óxido de zinco como material obturador em pulpectomias em dentes decíduos, uma revisão bibliográfica foi realizado com publicações dos últimos 5 anos, por meio de busca nas bases de dados: ScienceDirect, Google Scholar e Medline levando em consideração duas variáveis: a eficácia e os efeitos adversos do Calen. Por fim, Calen / ZO tem sido bem recebido no mercado odontológico devido à sua biocompatibilidade com o tecido dentário; mas certamente não há material 100\% ideal ainda, portanto, existem algumas ligeiras desvantagens do material.

Palavras-chave: Calen / ZO, pulpectomia, necrose, dentes provisórios, técnica de obturação, material obturador. 


\section{Introducción}

En el momento del nacimiento la erupción del órgano dentario no está presente. A los 6 meses suele ocurrir la erupción de los incisivos inferiores, siendo los primeros dientes deciduos perceptibles; fisiológicamente la dentición temporal muestra diastemas a lo largo de la arcada, con el objetivo de que la dentadura permanente tenga una erupción normal y correcta (1). Los dientes de leche han cumplido funciones en el organismo, como: habilidades masticatorias, la deglución y fonoarticulación, mantenimiento del espacio y de la estimulación del desarrollo maxilar para contener la fórmula dentaria definitive. En la mayoría de los casos los dientes primarios intervienen en el equilibrio de la musculature; ademas, de ser responsables de la estética, contención de los antagonistas en el plano oclusal y el estímulo para el desarrollo de los maxilares (2).

Una de las principales patologías que pueden afectar la dentición decidua, tenemos las enfermedades pulpares y periapicales, cuya etiología es mayormente de tipo bacteriana, traumatismos, iatrogénicos, químicos e idiopáticos, que causan un desequilibrio en los órganos dentarios (esmalte, dentina, pulpa); por lo tanto, la pulpa reacciona de forma negativa causando una inflamación que ocurre como respuesta a mecanismos directos o indirectos provocando una patología endodóntica primaria como es la pulpitis.

Las enfermedades pulpares en dientes deciduos, pueden contrarrestarse mediante un tratamiento de pulpotomía o de pulpectomía dependiendo el grado de afectación que presentan los dientes temporales; la ejecución operatoria que involucra la eliminación de la pulpa inflamada y las bacterias pueden tener éxito en el tratamiento de pulpectomía, al realizar un buen diagnóstico definitivo de la enfermedad, para manipular el campo operatorio es indispensable la asepsia seguida de un aislamiento para evitar contaminación en la cavidad bucal, además la preparación biomecánica que consiste en limpiar y desinfectar de modo apropiado los conductos radiculares anterior a la obturación (3).

Muchas veces la instrumentación biomecánica no asegura la eliminación de las bacterias, especialmente en la pulpectomía que involucra los túbulos dentinarios y a su vez las ramificaciones de los mismos, es indispensable el uso de medicamento antibacteriano que ayude a la esterilización del conducto radicular.

Debido a este hecho, los investigadores buscan medicamentos intraconducto con efecto antimicrobiano, buscando erradicar las bacterias aerobias, anaerobias y facultativas; recientemente, los materiales biocerámicos han ganado popularidad en la práctica endodóntica, el uso del hidróxido de calcio (Calen) considerado como un tratamiento intraconducto (4).

Los medicamentos usados como antiséptico durante la historia han sido muchos; el arsénico fue introducido por S. Spooner en 1936, utilizado para mitigar el dolor y la destrucción de la pulpa. A.W. Harlam, en 1900, usó una solución de papaína para la absorción del tejido pulpar muerto. En esta fecha tomó popularidad también el peróxido de hidrógeno en solución para esterilizar los conductos radiculares. En 1906 J.P. Buckley, introdujo el tricresol y la formalina para la momificación del tejido pulpar. La clorhexidina en 1982, Delany y Cols. la usaron como agente antibacteriano e irrigante en la terapia endodóntica. El uso de materiales de hidróxido de calcio $\mathrm{Ca}(\mathrm{OH}) 2$ en endodoncia fue introducido por Bernhard W. Herman en 1920 (5).

En la pulpectomía para conservar gran parte del tejido dentario es importante la elección del material de obturación, en los que incluyen actividades bactericidas, biocompatibles y reabsorción del material a una velocidad similar que las raíces. Desde hace mucho tiempo en el medio encontramos los primeros materiales, como: Óxido de Zinc

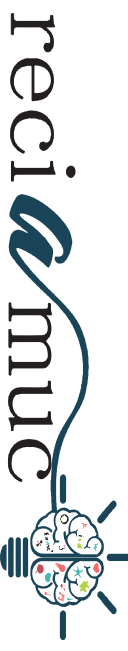


con Eugenol, Hidróxido de Calcio y material a base de yodoformo, entre otros (6). En la actualidad la pasta de Calen mezclada con óxido de zinc, es un nuevo producto obturador usado para pulpectomía en dientes temporales. Recientemente, Chawla et al., describieron una evaluación clínica radiográfica de una mezcla de pasta de Calen espesada con óxido de zinc, para la obturación de los dientes temporales. La estrategia tuvo como objetivo utilizar una pasta con una tasa de reabsorción similar a la de la reabsorción radicular fisiológica en los dientes temporale (7).

\section{Metodología}

Se realizó una revisión bibliográfica, mediante búsquedas en las bases de datos: ScienceDirect y Medline entre 2015 y 2020. Los criterios de inclusión fueron: todos los ensayos clínicos en humanos y animales sobre la efectividad, actividad microbiana seguridad y/o efectos adversos del Calen/ ZO en la pulpectomía, con datos estadísticos y publicados en los últimos 5 años. Las variables analizadas en este estudio fueron dos: la efectividad y los efectos adversos del Calen/ZO; finalmente, se registró el tamaño de las muestras, las pruebas estadísticas y el seguimiento de cada artículo.

\section{Estado del arte}

\subsection{Pulpectomía}

La pulpectomía es una técnica endodóntica usada en dientes primarios que remueve el tejido pulpar con la intención de reducir la población bacteriana de la pulpa contaminada, después de la preparación biomecánica se necesita tener los conductos radiculares limpios, para colocar el material obturador [20]. El objetivo primordial en la odontología pediátrica es poder conservar la dentición temporal hasta su exfoliación permitiendo la erupción de la dentición permanente; el tratamiento debe permitir la reabsorción fisiológica de la raíz y del material de obturación para no intervenir negativamente en la erupción de las piezas secun- darias (8).

El éxito del tratamiento de la pulpectomía consiste en la reducción y eliminación de los microorganismos patógenos intraconducto; por lo que se debe realizar una adecuada instrumentación del canal radicular, es fundamental la irrigación con solución antimicrobiana y la obturación con un material que tenga propiedades antibacterianas (8).

Los dientes primarios que presentan gran pérdida de estructura radicular (más de 2/3 de reabsorción) están contraindicados para realizar tratamiento de pulpectomía, así mismo en dientes con perforación del piso de la cámara pulpar o sin posibilidad de restauración; si radiográficamente se evidencia reabsorción interna o externa tampoco están indicados para el tratamiento, o cuando existe una extensa reabsorción ósea envolviendo la cripta del diente permanente sucesor o en pacientes con estado de salud general debilitado (9).

\subsubsection{Preparación biomecánica}

La preparación biomecánica es una fase del tratamiento endodóntico que va a permitir tener acceso directo y seguro a la región cementodentinaria, permitiendo la eliminación total del contenido pulpar ya sea vital o no vital, aséptico o necrótico, procurando no deformar el conducto. Es importante recordar la complejidad anatómica de las piezas deciduas y permanentes, debido a que difieren mucho entre sí, tanto externa como internamente (10).

\subsubsection{Etapas de la preparación biomecáni- ca:}

3.1.2.1. Exploración del conducto radicular: es el primer contacto que tiene el operador con el interior del conducto radicular y a través del cual será posible verificar:

- El número, la dirección y calibre de los conductos.

- La posibilidad del acceso al tercio api- 
cal (10).

La exploración ha sido de suma importancia para el reconocimiento del conducto. Es sustancial elegir el instrumento que se utilizara, antes de iniciar el procedimiento, para determinar la longitud de trabajo; a través de los instrumentos se puede palpar, logrando sentir y obteniendo la información necesaria (10).

Durante todo el tratamiento se usará un punto o borde de referencia, este hito será necesario siempre que se requiera observar una medida de referencia. Cuando hay ausencia de la superficie incisal o de la cúspide del diente que sirven como borde de referencia, es necesario reconstruirla o nivelar; el margen de referencia debe ser nítido y estable (10).

3.1.2.2. Odontometría (medición del diente): para obtener la longitud del diente a tratar se puede obtener mediante los métodos de Bregman y de Ingle, entre otros; para ejecutar estos métodos se toma una radiografía periapical del diente en tratamiento, con la lima en el interior del conducto (10).

Para comprobar las medidas utilizadas en la técnica de Bregman, se realiza con la ayuda de una regla milimétrica, a la luz de un negatoscopio, obteniendo:

- Longitud de la lima en la radiografía, a la que Ilamamos longitud aparente del instrumento (LAI).

- La longitud del diente en esta radiografía, a la que designamos longitud aparente del diente (LAD).

La exploración y la medición en dientes con varios conductos, se la realiza por separado; puede efectuarse en un solo procedimiento, aunque no es aconsejable en aquellos con poca práctica (10).

3.1.2.3. Limpieza del conducto radicular: en la pulpectomía, la limpieza involucra la eliminación del tejido pulpar contenido en el conducto dentinario.
La longitud de trabajo para la limpieza (LTL) corresponderá a la longitud real del diente (LRD), determinada mediante odontómetro, a la que se le reduce $1 \mathrm{~mm}$. Así:

$$
\mathrm{LTL}=\mathrm{LRD}-1 \mathrm{~mm}
$$

En las pulpectomías, casi siempre será suficiente la utilización de dos o tres limas para iniciar la limpieza del conducto y, de esa forma, crear el espacio necesario para que se pueda iniciar la conformación. La limpieza y conformación ayuda a remover las pequeñas porciones de tejido pulpar que suelen persistir en el conducto (10).

3.1.2.4. Conformación del conducto radicular: en los casos de pulpectomía, la conformación (o instrumentación) tiene por objetivo la creación de condiciones morfológicas y dimensiones para que el conducto pueda obturar de manera correcta (10).

Cuando las limas operan en el foramen apical o más allá de este, se producirá aumento de diámetro del canal radicular; denominamos zip a la deformación del foramen apical.

Se pueden realizar diferentes técnicas de conformación, que sean simples, prácticas y eficientes. Entre ellas están:

- Técnica tradicional o clásica.

- Técnica escalonada.

- Técnica corona-ápice sin presión.

- Técnica mixta (10).

\subsection{Soluciones de irrigación}

Es de suma importancia realizar el desbridamiento y desinfección completa de los conductos radiculares; uno de los procedimientos más relevantes en la terapia endodóntica es la irrigación de los conductos radiculares, logrando excelentes resultados en la remoción del barrido dentinario, eliminando bacterias, causantes de patologías pulpares y periapicales presentes en el conducto consiguiendo una correcta limpieza, 
conformación, y sellado tridimensional del sistema de conductos radiculares (11).

\subsubsection{Acido etilendiaminotetraacético (ED-}

TAC): Posee un $\mathrm{pH}$ de 7.3-7.4, se utiliza a una concentración de 15\% y está compuesto por: $17 \mathrm{~g}$ de EDTA ,8.84 g de cetavion, $9,25 \mathrm{ml}$ de $5 / \mathrm{N}$ hidróxido sódico y $100 \mathrm{ml}$ de agua destilada. El cetavión da acción antibacteriana, permitiendo eliminar los microbios debido al aumento de la permeabilidad (12).

\subsubsection{El ácido etilendiaminotetraacético} (EDTA): Actúa como agente quelante de iones metálicos; tiene la capacidad de desmineralizar y remover tejido inorgánico del barrido dentinario, se lo usa al 17\% (13).

3.2.3. Hipoclorito de sodio (NaOCl): Se presenta en concentraciones que van desde 0.5 hasta $5.25 \%$; logra la disolución de tejido orgánico, saponificación, transformación de aminoácidos en cloraminas o en sales de aminoácidos y la desodorización del sistema de conductos radiculares (14).

\subsubsection{Peróxido de hidrógeno o agua oxi-} genada (H2O2): Se utiliza el hidrógeno al $3 \%$ en endodoncia, debido a su acción efervescente y desinfectante, gracias a la liberación de oxígeno se eliminan bacterias anaerobias estrictas; después de usar el peróxido de hidrogeno, la irrigación final debe darse con hipoclorito de sodio para evitar la liberación del peróxido de hidrogeno (12).

3.2.5. Clorhexidina: Ayuda al control de la placa bacteriana y asimismo puede ser usada en varias concentraciones para la irrigación de conductos radiculares; la clorhexidina es un antiséptico bacteriostático y bactericida, pero carece de efecto disolvente de tejido (15).

3.2.6. Ácido cítrico: Se lo puede usar con combinación del $\mathrm{NaOCl}$ para potencializar su acción, presenta un pH bajo e interviene como agente quelante para eliminar el barrido dentinario; se lo usa a una concentración del 10\%. Presenta un efecto más potente a los 3 minutos, provoca una descalcificación mayor que EDTA al 17\% cuando se usa por más de un minuto (16).

\subsubsection{Solución salina: Es una solución que} no inflama ni irrita los tejidos orgánicos, no tiene propiedades bactericidas ni solvente de tejido orgánico. Esta solución es compatible con otras sustancias irrigadoras por lo que puede asociarse, tiene un efecto de desbridamiento y lubricación el sistema del conducto radicular (17).

\subsection{Medicación intraconducto}

La medicación intraconducto está justificada en caso de necropulpectomía, el éxito del tratamiento de la pulpectomía está influenciado por la eliminación de las bacterias de los conductos infectados (18). Para este procedimiento se utilizan algunos materiales como:

\subsubsection{Paramonoclorofenol alcanforado:}

Tiene baja tensión superficial, que facilita la difusión del medicamento a través de los túbulos dentinarios y de los conductos radiculares. A las 24 horas de su colocación su efecto desaparece en un 90\% (19).

3.3.2. Formocresol: Se ha usado como fijador hístico, principalmente en los dientes temporales en las biopulpectomías, con la finalidad de calmar el dolor. Fue introducido por Buckley a principios del siglo xx y consiste en $19 \%$ de formaldehído, 35\% de cresol, $15 \%$ de glicerina y agua; el formaldehído y el cresol, son parte activa del medicamento que permite la difusión (19).

3.3.3. Pasta Ledermix: combinación de antibióticos como la tetraciclina, demeclociclina HCL, y un corticosteroide, el acetónido de triamcinolona, en una base de polietilenglicol. Estos componentes son capaces de difundir a través de los túbulos dentinarios y el cemento para llegar a los tejidos periodontales y periapicales (18).

3.3.4. Pasta tri- Antibiótica: conformada por ciprofloxacino, minociclina y metronidazol, 
es eficaz contra el Escherichia coli presente en una dentina infectada. La pasta triple antibiótica usada en la desinfección de dientes inmaduros con periodontitis apical ha mostrado una eficacia. Esta pasta antibiótica puede producir resistencia bacteriana (18).

3.3.5. Hidróxido de calcio: Este es el único medicamento que estimula la cicatrización biológica y la formación de tejido duro sobre la pulpa radicular amputada. El hidróxido de calcio es un antiséptico, con un pH alcalino, que ayuda a prevenir la invasión bacteriana, se ha utilizado para recubrimientos pulpares directos, en dientes permanentes jóvenes (18).

\subsection{Materiales de obturación}

3.4.1. Materiales a base de Oxido de zinc Eugenol (ZOE): Este cemento presenta un $\mathrm{pH}$ neutro, tiene una buena biocompatibilidad con los tejidos duros, blandos y presenta una menor irritación pulpar. Posee una baja conductibilidad térmica y eléctrica, pero es buen sellador de los conductos; así mismo, pierde sus características antibacteriales luego de ser introducido en Ios conductos (8). El ZOE está contraindicado debajo de resinas sintéticas, acrílicas o compuestos, debido a que impiden la polimerización y la resina por tanto solo se endurecerá en la superficie (20).

3.4.2. Pasta de Guedes Pinto: es una pasta compuesta por $0,30 \mathrm{~g}$ de yodoformo, 0,25 $\mathrm{g}$ de Rifocorty $0,1 \mathrm{ml}$ de paramonoclorofenol. Este material tiene un éxito alto $(97,8 \%)$ (8). Para efectuar un tratamiento pulpar, la pasta de Guedes Pinto tiene la capacidad de eliminar las bacterias de los tejidos inflamados, de los dientes primario; es un compuesto farmacológico que se utiliza como material obturador, se prepara a base de antisépticos, corticoide y antibiótica (21).

3.4.3. Vitapex: contiene: yodoformo (40.4\%), hidróxido de calcio (30\%), aceite de silicón $(22.4 \%)$ y otros $(6.9 \%)$. La velocidad de reabsorción del material es apro- ximadamente similar al de las raíces de los temporales de forma fisiologica, es radiopaco, tiene fácil manipulación y colocación dentro del conducto, posee poder antibacteriano (8).

3.4.4. MTA: Es un nuevo material desarrollado para endodoncia. El MTA es un cemento muy alcalino, con un $\mathrm{pH}$ de 12,5. Este $\mathrm{pH}$ es muy similar al del Hidróxido de Calcio, y puede posibilitar efectos antibacterianos. Presenta baja solubilidad y una radiopacidad mayor que la dentina. MTA favorece la formación de hueso y cemento, y puede facilitar la regeneración del ligamento periodontal sin provocar inflamación (22).

3.4.5. Calen: es una pasta alcalina, ligeramente amarillenta, de consistencia uniforme y cremosa. Está compuesta por hidróxido de calcio al 49,77 g\%; óxido de zinc; colofonia; PEG 400 y glicerina 100,00 g\%. Este material está indicado en: biopulpectomias, necropulpectomia, exudado excesivo, reabsorción externa e interna, dolor postoperatorio, en el tratamiento de dientes con ápice incompleto, fractura de raíz, perforaciones, fístulas persistentes y lesiones periapicales refractarias al tratamiento endodóntico convencional. Para usar esta pasta de Calen en pulpectomía, se la debe mezclar con óxido de zinc formando un material con mayor consistencia (Calen/ZO). Al contener esta pasta hidróxido de calcio, presenta una buena biocompatibilidad, un $\mathrm{pH}$ elevado, presenta una reabsorción sincronizada con el tejido radicular, la pasta de Calen en dientes permanentes es usada como medicamento intraconducto. Al mezclar esta pasta con ZO le da una buena consistencia al material, pero la desventaja es que puede producir una leve inflamación del tejido, debido a la presencia del zinc. El Calen tiene un periodo de actuación: Debe permanecer en el canal radicular un mínimo de 7 días y un máximo de 60 días; exudado excesivo persistente, debe permanecer en el canal radicular por un mínimo de 14 días y máximo de 60 días, actuando como medicación intraconducto (23). 


\section{Discusión}

En odontopediatría los materiales de obturación para pulpectomía de dientes deciduos, deben cumplir propiedades que ayudan a mantener los dientes primarios en la cavidad bucal hasta su proceso de exfoliación.

En un estudio realizado por Silva et al., mencionan que las pastas a base de hidróxido de calcio se pueden usar como material de relleno en los dientes temporales, debido a la reabsorción armónica del material y las raíces; quienes realizaron investigaciones en animales, cumpliendo con los protocolos establecidos por el Comité de Cuidado Animal de la Universidad de São Paulo (Protocolo \# 02.1.1460.53.0). Tomaron como muestra a dos perros de 12 y 18 meses de edad, con un peso aproximado de 8 a 10 $\mathrm{kg}$; en el ensayo escogieron varios dientes, como: segundos, terceros y cuartos premolares mandibulares, y en el maxilar se seleccionaron los segundos y terceros premolares. Para esta investigación se consideró a la pasta de Calen (hidróxido de calcio) espesado con óxido de zinc, con el objetivo de disminuir la tasa de reabsorción, buscando simultáneamente que la reabsorción de los dientes primarios sea de manera fisiológica; el estudio comprendió en analizar hallazgos histopatológicos en materiales de obturación con pastas compuestas en el grupo I: Calen espesada con óxido de zinc; grupo II: Pasta a base de yodoformo, rifocort y paramonoclorofenol alcanforado; grupo III: Oxido de zinc con cemento eugenol (ZOE) y grupo IV: solución salina estéril; la aplicación de estos materiales se hizo con una lima $\mathrm{K}$. De esta manera, con respecto a la biocompatibilidad los resultados de este estudio fueron en el grupo I y IV satisfactorios, debido a que no presenta reabsorción ósea; sin embargo, en el grupo del Calen/ ZO se puede observar engrosamiento del ligamento periodontal en 3 de las 12 raíces tratadas, por lo que es considerado un material óptimo; también presenta una gran cantidad de fibras y células de colágeno, existió una leve inflamación que no fue tras- cendental. En cambio, para el grupo II y III el resultado no es favorable debido a la reabsorción que presenta en el ápice de los dientes primarios, por lo que se ha observado que el paramonoclorofenol alcanforado tiene la desventaja de reducir fibras, fibroblastos y vasos; así mismo, en el grupo del ZOE que contiene iones de eugenol actúan como un elemento inflamatorio, provocando el engrosamiento del ligamento periodontal (7).

Por otra parte, Cassol y col., en el estudio realizado en el Departamento de Odontología Pediátrica y Ortodoncia, en la Universidad Federal de Río de Janeiro, Rio de Janeiro, Brasil. Las personas que participaron en el estudio lo hicieron de forma voluntaria, los padres o tutores recibieron toda la información sobre el procedimiento de pulpectomía, como las ventajas y los posibles riesgos del tratamiento. Para el proceso de este estudio la muestra consistió en 27 dientes primarios con necrosis o pulpitis irreversible, causado por caries dental o trauma en 23 niños (2-7 años); usando dos materiales para la obturación dental, conforma el grupo I: (pasta de yodoformo $n=13$ ) y el grupo II (pasta Calen® / ZO n = 14). En el estudio se observó un alto nivel ideal de relleno de los conductos radiculares en el grupo Calen/ ZO, se cree que al engrosar con el óxido de zinc mejora la consistencia y favorece su inserción en el conducto; asimismo, en el grupo de la pasta de yodoformo muestra excelente propiedad antibacteriana y antiinflamatoria, pero hay una fácil absorción; sin embargo, los productos a base de yodoformo pueden provocar la decoloración de la corona, limitando su uso en dientes anteriores. Las pastas de hidróxido de calcio (Calen) son ampliamente utilizadas porque no causan ese tipo de deterioro, presentaron baja toxicidad y propiedades antibacteriana, antifúngica y buena compatibilidad (24).

El Calen, considerando que es un producto relativamente nuevo en el mercado, diversos estudios lo han identificado como buen material de obturación debido a varios fac- 
tores; en el estudio realizado por Silva et al., se compararon los siguientes materiales: el grupo I una pasta a base de hidróxido de calcio (Calen ${ }^{\circledR}$ ) ) en combinación con varias proporciones (1: 0.5; $1: 0.65 ; 1: 0.8$; 1: 1) de óxido de zinc (ZO); el grupo II un cemento de óxido de zinc y eugenol (ZOE); y en el grupo III un cemento endodóntico a base de hidróxido de calcio (Sealapex $\AA^{\circledR}$ ). En este estudio se tomó en cuenta el tiempo de fraguado, los valores de $\mathrm{pH}$, la radiopacidad, la solubilidad, los cambios dimensionales, la fluidez y el análisis químico por espectrofotometría de rayos $X$ de energía dispersiva (EDX). A realizar la comparación de los materiales se construyeron moldes cilíndricos de plástico; se estudió el tiempo de fraguado siendo favorable para el grupo I en comparación con los otros grupos; el tiempo de fraguado del Calen fue más rápida en las porciones de óxido de zinc que se mezclaron con 1: 0.65 y 1: 0.5. Al seguir analizando las muestras el grupo del Sealapex® y ZOE exhibieron los valores de pH pico más bajos entre todos los materiales investigados, mientras que la pasta Calen $₫$ espesada con ZO en proporciones 1: 0.5 y 1: 0.65 exhibió los valores de pH más altos en todos los puntos de tiempo evaluados. En relación al análisis de la radiopacidad todos los materiales de obturación exhibieron una radiopacidad similar; en cambio, el grupo III Sealapex exhibo una solubilidad más baja en comparación al resto de materiales; pero las porciones 1: 0.5 y 1: 0,65 junto con el ZOE tuvieron los valores de solubilidad más altos, demostrando ser solubles en el agua (H2O). Han comprobado que los cambios de dimensión han sido muy bajos en el Sealapex; todas las porciones de Calen con óxido de zinc han presentado un alto cambio dimensional, las porciones 1: 0.8, 1: $1 \mathrm{y}$ ZOE, comparado con el grupo III, revelaron un cambio dimensional más alto; aunque, las raciones de 1: 0.5 y 1: 0.65 , alcanzaron los valores más altos en el cambio dimensional, en comparación al resto de grupos. La fluidez de los materiales es muy importante, por lo que en una porción 1:1 de la pasta de Calen/ZO no presentó ningún flujo; el Sealapex estableció el mayor flujo con una discrepancia característica con el resto de los grupos continuado de las combinaciones de pasta de Calen + ZO en magnitudes de 1: 0.5 y 1: 0.65. El análisis estadístico de la espectrofotometría de rayos $\mathrm{X}$ no mostró contrastes reveladores entre ninguno de los materiales evaluados; aunque, se manifestó que la liberación de calcio disminuyó progresivamente en similitud directa con el aumento de ZO adherido a la pasta de Calen, pero la liberación de zinc aumentó paulatinamente con la aplicación de ZO en el Calen (25).

Existen más resultados que avalan la actividad microbiana del Calen, sin embargo, en el estudio de Pilownic et al., evaluaron cuatro materiales de obturación que se pueden usar en dientes temporales; Grupo | MTA, Grupo || cemento de óxido de zinc y eugenol (ZOE), el Grupo III una mezcla premezclada de hidróxido de calcio y yodoformo (Vitapex) y el Grupo IV Calen espesada con óxido de zinc (Calen/ZO). Dentro del estudio se valoró el $\mathrm{pH}$, la radiopacidad, el efecto antimicrobiano, citotoxicidad y la biocompatibilidad de los materiales de obturación en pulpectomía. Para el control del $\mathrm{pH}$ se lo realizó mediante un medidor de $\mathrm{pH}$ sympHony, en un periodo de 1,3,7,15 y 30 días; al calcular el $\mathrm{pH}$ el material basado en MTA fue semejante al del Calen/ZO dentro del ciclo práctico. A los 30 días el MTA tuvo el pH más alto con respecto al resto de materiales y el Vitapex presentó el pH más inferior. En la radiopacidad se utilizaron placas acrílicas, los prototipos se los ubica en un sensor digital radiográfico con un tiempo de exposición de 0,2s con una distancia de enfoque de $30 \mathrm{~cm}$; obteniendo una radiopacidad más alta en el Vitapex y el ZOE en comparación a los otros materiales del ensayo, el Grupo I MTA mostró valores más bajos de radiopacidad. Al evaluar los efectos antimicrobianos se usó un cultivo de Enterococcus faecalis, los mismos que se plantaron y clonaron durante la noche a $37^{\circ} \mathrm{C}$; la 
persistencia bacteriana se tasó durante las 24-48 h a $37^{\circ} \mathrm{C}$, después de la incubación. Con el MTA se obtuvo un 99,9\% de eliminación de los microorganismos E. faecalis, durante la exposición de $4 \mathrm{~h}$ del material; mientras que los materiales del grupo II, III, y IV a sus 24 h de exposición obtuvieron una muerte bacteriana del 98\%. Se obtuvo una muestra $(n=5)$ en pacientes humanos sometidos a cirugía oral; mediante la prueba MTT se evaluó la viabilidad celular en los fibroblastos gingivales de los participantes, para estimar la citotoxicidad después de la incubación durante 1, 3 y 7 días. La prueba MTT reveló una viabilidad más alta en las células expuestas al Vitapex, el ZOE presentó las viabilidades más bajas; sin embargo, no hubo diferencias estadísticas en la viabilidad de los materiales basados en MTA y Calen/ZO. Los investigadores usaron 15 ratas ( $n=5$ por grupo en cada punto de tiempo), para determinar la biocompatibilidad de los materiales, analizándolos de manera histológica durante 15, 30 y 60 días. El Vitapex y el MTA a los 15 días tuvieron una inflamación moderada, mientras que los grupos ZOE y Calen/ZO presentaron una inflamación de moderada a severa; a los 30 días se observó celular con inflamación leve con el MTA, el resto de materiales provocaron una moderada inflamación; finalmente, a los 60 días el grupo I, II y III ostentan una leve inflamación, la mayoría de las muestras de Calen + ZO respondieron con un infiltrado inflamatorio moderado. La inflamación persiste en el Calen/ZO debido a la mayor concentración de zinc en el material, que contribuye en el proceso inflamatorio (26).

El tratamiento de la pulpectomía en los dientes temporales debe tratar de mantener la integridad de los tejidos apicales y periapicales, así como la integridad del germen del diente sucesor permanente. Así, Pinto y col., evaluaron el ZOE y el Calen mezclado con óxido de zinc; optaron por una muestra de 26 pacientes (31 dientes), la edad fue entre los 2 a 5 años. Al realizar el ensayo se tomaron algunos criterios de inclusión, los cuales fueron: el paciente debe presentar necrosis pulpar por traumatismo al menos en un diente anterior; una necrosis pulpar con signos clínicos y radiográficos; los dientes deben poseer al menos 2/3 de raíz; diente posiblemente saludable. Todos los padres y tutores fueron informados de las ventajas y desventajas de los procesos operatorios tratados; así posteriormente, se procedió a que firmen el consentimiento informado. Durante el procedimiento si el paciente contaba con dos dientes, uno era rellenado con ZOE y el otro con Calen/ZO; la técnica de obturación consistió en introducir las pastas con una lima manual (Limas K-Flex 20 o 25) y con una bolita de algodón estéril usada en el léntulo, para comprimir las pastas en el conducto radicular. A los pacientes se les realizó un proceso de control a los 1,3,6 meses 1 un año después del tratamiento; un 48,3\% de los casos se usó ZOE y el otro 51,6\% la pasta de Calen/ZO. El porcentaje de éxito en esta investigación, fue: el ZOE en un 93,3\% y la pasta de Calen engrosada con óxido de zinc obtuvo el $87,5 \%$ de éxito (27).

La preparación biomecánica y la obturación de los conductos radiculares son primordial para tener éxito en el tratamiento, es recomendable que el material de relleno sea fagocitable. Según el ensayo realizado por Queiroz et al., seleccionaron ciento dos ratones machos de 6 a 8 meses de edad con un peso de 15 a $20 \mathrm{~g}$; se establecieron 11 grupos al azar, los animales fueron repartidos de la siguiente manera: Grupos I, II, III: Calen / ZO durante 7, 21 y 63 días; Grupos IV, V, VI: Sealapex durante el mismo tiempo; el Grupos VII, VIII, IX: ZOE con el mismo tiempo respectivamente; Grupos X y XI: tubo vacío durante 7 y 21 días. Cada grupo del I al IX contenía 10 animales, en cambio, los grupos X y XI poseían 6 animales cada uno; estas pastas se mezclaron de acuerdo con las instrucciones del fabricante. Los investigadores realizaron una observación histológica y siguieron el análisis microscópico semicuantitativo realizado por Silva et 
al., donde se utilizaron sistemas de puntuación de cuatro puntos (0-3) para evaluar los tejidos junto al implante, de acuerdo con las siguientes cuantificaciones: Formación de fibras de colágeno, puntuación $0=$ ausente; puntuación 1=leve; puntaje 2 = moderado; y puntaje 3 = intenso. En el resultado de la formación de las fibras de colágeno, en el grupo de control se presentó una mayor formación a los 7 días; en la fase de los 21 días se obtuvo una mayor formación de las fibras de colágeno en el Calen/ZO y Sealapex; en cambio, tuvo una discrepancia significativa entre todos los materiales probados y el de control con el Calen / ZO y ZOE. Al realizar el análisis de todos los materiales a los 63 días, expuso una diferencia significativa entre todos acerca de la creación de fibras. A los 7 días también se examina la inflamación, dando como resultado un contraste revelador entre todos los materiales del ensayo y el de control; se produjo una menor inflamación por parte del Calen/ZO en comparación con el resto de materiales probados. Todos los materiales y de control no presentaron infiltrado inflamatorio en la mayoría de las muestras, a los 21 días; después, a los 63 días el Calen/ZO sigue presentando una inflamación menor que el resto de materiales, siguiendo el mismo patrón de respuesta de los 7 días. En el análisis microscópico cuantitativo, el grupo de control tuvo diferencias reveladoras con el Calen/ ZO y el Sealapex, fue en el curso de los 7 días; las muestras de control tienen superficie de tejido más grande y el Calen/ZO más pequeñas. En el ciclo de los 21 días, el área de tejido disminuyó relativamente en todas las pastas detalladas y el grupo de control. La zona del tejido se redujo aún más a los 63 días, para el Calen/ZO y Sealapex; en cambio, aumentó para el ZOE. Posteriormente, se evaluó el espesor de la regeneración tisular guiada (RGT). No existió ningún tipo de diferencia entre los grupos a los 7 días; se observó a los 21 días un aumento de grosor en el tejido, en respuesta a todos los materiales de relleno, pero se comprimió en el grupo de control. Las muestras a los
63 días, no tuvieron diferencia alguna entre los grupos (28).

En otro estudio Queiroz et al., buscaron conocer la actividad antibacteriana in vitro de 5 cepas bacterianas diferentes, que se usaron como microorganismos indicadores en el estudio: Kocuria rhizophila, Enterococcus faecalis, Estreptococo mutans, Escherichia coli, Staphylococcus aureus; las evaluaron mediante una prueba de difusión en agar (técnica de pocillo de agar). En este ensayo, los microbios fueron sometidos a diferentes materiales de obturación, estos fueron: cemento de óxido de zinc y eugenol (ZOE); pasta de Calen espesada con óxido de zinc (Calen/ZO); sellador Sealapex; sellador EndoREZ. Los investigadores trabajaron con tres grupos de control, fueron: pasta de Calen, digluconato de clorhexidina al 1\% (CHX); agua destilada. Todos los materiales se utilizaron inmediatamente después de mezclar; utilizaron 6 placas para cada germen. Usando la prueba de difusión en agar, las muestras de K. rhizophila con respecto a la pasta de Calen, Calen/ZO y el Sealapax, reprimen el crecimiento bacteriano en una escala del 20,67 a 21,33 mm; Tchaou y col., quien estudio el ZOE revela mayor inhibición en bacterias gramnegativas; pero en el ensayo presente el ZOE y CHX 1\%, presentaron restricción de crecimiento microbiano con diámetros de 32,67 y 31,5 mm; en un estudio realizado por Eldeniz et al., no observó actividad antibacteriana de EndoREZ contra E. faecalis, S. aureus y P. aeruginosa; en la actual investigación EndoREZ originó una inhibición con diámetro medio de $7 \mathrm{~mm}$. El Calen/ZO, continuado de pasta de Calen y $\mathrm{CHX} 1 \%$ impidieron el crecimiento bacteriano frente a $\mathrm{E}$. faecalis, con un diámetro de 22, 20 y 18 mm, individualmente; el agua destilada y el EndoREZ no expuso actividad antibacteriana; por otro lado, Miyagak et al. han demostrado actividad antimicrobiana de Sealapex contra E. faecalis

, S. aureus y Candida albicans, utilizando la prueba de difusión de agar; en cambio, en la investigación actual el Sealapex y el 
ZOE ostentaron acción antibacteriana media, con áreas de abstención de crecimiento microbiano de 13,00 y 9,00 mm de diámetro. En los resultados de la cepa de S. mutans, no hubo diferencias significativas en la pasta de Calen, Calen/ZO, Sealapex y ZOE, provocando un diámetro de 12.33, 12.67, 11,00 y $11,00 \mathrm{~mm}$ de inhibición del crecimiento bacteriano, equitativamente; en la $\mathrm{CHX} 1 \%$ las cepas S. mutans, presentan un área extensa de inhibición del crecimiento bacteriano con 24,17 mm de diámetro; en esta bacteria el EndoREZ y el agua destilada no exhibió actividad antimicrobiana. En el E. coli, el agua destilada y EndoREZ no tuvieron acción antimicrobiana; el ZOE y la $\mathrm{CHX} 1 \%$, en la cepa de E. coli mostró una superficie amplia de inhibición de la evolución bacteriana, con diámetro individual de 23,67 y 19,33 mm, teniendo diferencias estadísticas entre los dos materiales; entre la pasta de Calen y Calen/ZO expuso un área de inhibición medio en la evolución bacteriana 15,50 y $16,00 \mathrm{~mm}$. La última muestra, tuvo una inhibición de crecimiento bacteriano contra S. aureus de: $23 \mathrm{~mm}$ en la $\mathrm{CHX}$ $1 \%, 20 \mathrm{~mm}$ en el Sealapex, $19 \mathrm{~mm}$ en la pasta de Calen, $18 \mathrm{~mm}$ en ZOE, $17 \mathrm{~mm}$ en Calen/ZO Y 8mm en el EndoREZ (29).

Por otra parte, Caldeira y col., realizaron una investigación en la que evaluaron 100 dientes, de los cuales solo 43 cumplieron los criterios señalados en el ensayo. Los participantes del estudio corresponden a ambos sexos, en un rango de 4 a 11 años de edad; antes de realizar la intervención operatoria, informaron a los padres o tutores del proceso que se llevará a cabo en la investigación; después de esto, firmaron el consentimiento informado. Para la elección de la muestra, se efectuó un examen clínico y radiográfico de los dientes, de acuerdo a los siguientes criterios: molares inferiores primarios con caries profunda, dientes con señales de dolor espontáneo, dientes con dolor incitado o retirado, ausencia de fístula o absceso, ausencia de reabsorción interna o externa y dientes con posibilidad de res- tauración. Se compararon dos materiales de obturación, en la biopulpectomia con una instrumentación manual; Grupo I: pasta de Calen mezclada con ZO (Calen/ZO) $(n=21)$, Grupo II: pasta de hidróxido de calcio y yodoformo (Feapex) (N=22); para implantar el material de relleno en los conductos radiculares, el grupo I lo implanta con una jeringa Centrix de punta $N^{\circ} 4$, el Feapex posee una jeringa con punta endodóntica descartable, logrando introducir directamente al conducto; además, con una lima $N^{\circ} 15$, se ayuda a compactar el material en las paredes de los canales radiculares. Los dientes deciduos fueron evaluados clínica y radiográficamente a los 3, 6 y 9 meses después del tratamiento. Se retiraron 3 participantes luego del tratamiento, modificando así la muestra; en el grupo I se retiraron 2 y en el grupo II se retiró 1 . Como resultado clínico y radiográfico a los 3 meses, los 2 grupos proyectaron radiográficamente lesiones periapicales; a los 6 y 9 meses un diente más reveló fallas radiográficas en ambos grupos; a los 3, 6 y 9 meses los dientes manipulados manifiestan clínicamente una efectividad del 100\% con los dos materiales. También, se exploró radiográficamente la calidad de relleno de los canales radiculares, siendo más satisfactorio para el Calen/ZO: en la raíz M, 13 piezas lograron un $61,9 \%$ de satisfacción y en 16 dientes la raíz D obtuvo $76,2 \%$; en cambio, el Feapex presentó una mínima diferencia en relación al otro material, teniendo un $59,1 \%$ en la raíz $M$ de 13 piezas y en los 16 dientes las raíces distales lograron $72,7 \%$; cuatro dientes presentaron sobre obturación, siendo perjudicial para el grupo II, debido a que 3 pertenecían a este grupo. Otro punto que exteriorizaron en el presente estudio, fue la reabsorción de material; a los 3 meses el material de obturación se reabsorbe a la misma velocidad que las raíces del grupo I, con un porcentaje del $94,7 \%$ y 90,5\% en el Feapex; a los 6 meses el grupo I presenta un $84,2 \%$ y $100 \%$ el conjunto II; a los 9 meses es satisfactorio para los dos grupos, teniendo un $100 \%$ de reabsorción del tejido dental acompañado del material 
de relleno. En el análisis de las condiciones de restauración, a los 9 meses la puntuación Alfa, presenta clínicamente un $72,5 \%$ de satisfacción en 29 dientes; al usar la puntuación de Charlie, se obtuvo en 11 dientes un $27,5 \%$ teniendo fallas en las restauraciones (30).

Aunque se han propuesto varios materiales de obturación, en su mayoría con grandes ventajas, hasta la actualidad ningún material utilizado en dientes primarios cumple con todos los requisitos de un material de relleno para la raíz.

\section{Conclusión}

A pesar que, la pasta Calen es un nuevo producto en el mercado, con los resultados expuestos se observa que, la pasta de Calen mezclada con óxido de zinc (Calen/ZO) presenta algunas propiedades que lo hacen destacarse como pasta obturadora para pulpectomías de dientes deciduos como: el valor del $\mathrm{pH}$ es más alto, radiopacidad similar a otros materiales, buena biocompatibilidad como material obturador, impidiendo reabsorción ósea, buena estabilidad, produciendo un alto nivel de obturación en los conductos radiculares; baja toxicidad y propiedades antibacterianas, el tiempo de fraguado del Calen/ZO es más rápido en comparación con otros materiales; pero su principal desventaja, es la producción una leve reacción inflamatoria, debido a las partículas de óxido de zinc.

\section{Bibliografía}

1. Núñez K. Importancia de los mantenedores de espacio en dentición temporal. 2015;30. Disponible en: http://repositorio.usfq.edu.ec/bitstream/23000/5078/1/123629.pdf

2. Valdez M, Manuel JJ, Alfaro I, Fiorella I, Valdez M, Manuel JJ. UNA INSTITUCIÓN PÚBLICA DE LA PROVINCIA DE Universidad Católica Santo Toribio de Mogrovejo. 2019;1-47.

3. Nicole CDV, Ollague M. Análisis histológico de un tratamiento de conductos realizado hace 40 años : reporte de un caso . 2019;6(2):1-3.

4. Universidad Central de Venezuela. Facultad de
Odontología. HF, Bonetti Filho I, López Ampuero BP. Acta odontológica venezolana. [Internet]. Vol. 46, Acta Odontológica Venezolana. Facultad de Odontología de la Universidad Central de Venezuela; 2008 [citado el 25 de agosto de 2020]. 159-164 p. Disponible en: http:// ve.scielo.org/scielo.php?script=sci_arttext\&pi$\mathrm{d}=$ S0001-63652008000200010\& $\mathrm{lng}=$ es\&nrm $=\mathrm{i}-$ so\&tlng =es

5. All Documents [Internet]. [citado el 25 de agosto de 2020]. Disponible en: https://www.mendeley. com/library/

6. Luna S. Frecuencia de Pulpectomía, niños de 5-8 años de edad. Facultad Piloto de Odontología, clínica de Odontología Infantil III periodo 2014-2015. 2014;

7. da Silva LAB, Leonardo MR, de Oliveira DSB, da Silva RAB, de Queiroz AM, Hernández PG, et al. Histopathological evaluation of root canal filling materials for primary teeth. Braz Dent $\mathrm{J}$. 2010;21(1):38-45.

8. Escalaya Carolina. Pulpectomía y materiales de obturación. Odontol Pediatr. 2009;8(2):31-5.

9. 9. Fabricio T, Cevallos M. UNIVERSIDAD CENTRAL DEL ECUADOR CARRERA DE ODONTOLOGÍA temporales, realizados en la Clínica de Odontopediatría de la Universidad Odontóloga AUTOR : Joselyn Tatiana Lagos Jácome. 2019;

10. (99+) (PDF) Soares \& Goldberg - ENDODONCIA - TECNICA Y FUNDAMENTOS | Dr. Carlos San Martin D. - Academia.edu [Internet]. [citado el 25 de agosto de 2020]. Disponible en: https://www. academia.edu/8226348/Soares_and_Goldberg_ ENDODONCIA_TECNICA_Y_FUNDAMENTOS

11. GUAYAQUIL, ABRIL, 2019 Ecuador. 2019;

12. CARRERA DE ODONTOLOGÍA TEMA: " TENDENCIAS DE TÉCNICAS DE IRRIGACIÓN DE LOS ESPECIAL ISTAS EN ENDODONCIA DE ECUADOR ". AUTOR ( ES ): PAREDES CHICHANDE KAREN MICHAEL Trabajo de titulación previo a la obtención del grado de ODONTÓLOGA TUTOR : GUERRERO FERRE. 2016;

13. 1Fátima Carolina Vizcarra Erazo. 2019;

14. Mena JC. Eficacia de dos sistemas de irrigación en endodoncia: jeringa convencional y endoactivator en la desinfección del sistema de conductos radiculares [Internet]. 2019. Disponible en: http://repositorio.ug.edu.ec/handle/redug/40155

15. UNIVERSIDAD CENTRAL DEL ECUADOR CARRERA DE ODONTOLOGÍA "Remoción de barrillo dentinario usando como irrigación final

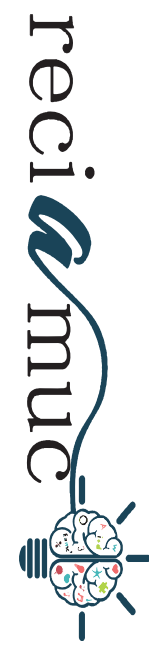


EDTA al $17 \%$ seguido de $\mathrm{NaOCl}$ al $5,25 \%$ o con una nueva solución irrigante ( ácido etilendiaminotetraacético más digluconato de clorhex. 2017;

16. UNIVERSIDAD CENTRAL DEL ECUADOR PROTOCOLO DE IRRIGACIÓN FINAL CON EDTA E HIPOCLORITO DE SODIO CON ACTIVACIÓN Y SIN. 2017;

17. Nataly A, Pinargote S. UNIVERSIDAD DE GUAYAQUIL DEL TÍTULO DE ODONTÓLOGO TEMA : AUTOR : Tutor : 2012;1-42.

18. Gina DRA, Armas V. UNIVERSIDAD DE GUAYAQUIL ODONTÓLOGA TEMA DE INVESTIGACIÓN: TIPOS DE MEDICACIÓN INTRACONDUCTO UTILIZADOS EN PULPOTOMÍAS DE DIENTES TEMPORARIOS . FIALLO ERAZO ANDREA NATALIA TUTORA : 2020;

19. No 主観的健康感を中心とした在宅高齢者にお ける 健康関連指標に関する共分散構造分析Title. 2020;21(1):1-9. Disponible en: https://doi. org/10.1016/j.solener.2019.02.027\%0Ahttps:// www.golder.com/insights/block-caving-a-viable-alternative/\%0A???

20. Ertürk $A$ (2011) "A CPI the ODA of $C$ and $T$ in $A$. No TitleÉ? Ekp. 2017;13(3):1576-80.

21. Nacional U, San MDE, Carmen A, Gutierrez P. Tratamiento pulpar en dientes deciduos con pasta Guedes Pinto modificada. 2017;

22. Biedma Perea M. Valoración del tratamiento de la pulpotomía con MTA en dientes temporales vitales. Depos Investig Univ Sevilla [Internet]. 2014; Disponible en: http://hdl.handle.net/11441/57158

23. Мещерякова ЛМ, Понтак ЛС. хими я No Title.
24. Cassol DV, Duarte ML, Pintor AVB, Barcelos R, Primo LG. Iodoform Vs calcium hydroxide/ zinc oxide based pastes: 12-month findings of a randomized controlled trial. Braz Oral Res. 2019;33:1-10.

25. Segato RAB, Pucinelli CM, Ferreira DCA, Daldegan $A$ de $R$, da Silva RS, Nelson-Filho P, et al. Physicochemical properties of root canal filling materials for primary teeth. Braz Dent $\mathrm{J}$. 2016;27(2):196-201.

26. Pilownic KJ, Gomes APN, Wang ZJ, Almeida LHS, Romano AR, Shen Y, et al. Physicochemical and biological evaluation of endodontic filling materials for primary teeth. Braz Dent $\mathrm{J}$. 2017;28(5):578-86.

27. Cultur A, Place-name TE, Secretary T, Society EP, Muhr K, Mac A, et al. No 主観的健康感を中心と した在宅高齢者における 健康関連指標に関する共 分散構造分析. Title. Geographie. 2009;18(April 2007):2014.

28. de Queiroz AM, Assed S, Consolaro A, Nelson-Filho $\mathrm{P}$, Leonardo MR, Silva RAB, et al. Subcutaneous connective tissue response to primary root canal filling materials. Braz Dent $\mathrm{J}$. 2011;22(3):203-11.

29. de Queiroz AM, Nelson-Filho P, da Silva LAB, Assed S, da Silva RAB, Izabel YI. Antibacterial activity of root canal filling materials for primary teeth: Zinc Oxide and Eugenol Cement, calen paste thickened with Zinc Oxide, Sealapex and EndoREZ. Braz Dent J. 2009;20(4):290-6.

30. UNIVERSIDAD FEDERAL DE ALFENAS DESEMPEÑO DE DOS MATERIALES OBTURANTES EN BIOPULPECTOMÍAS DE MOLARES DECIDUALES : ESTUDIO CLÍNICO ALEATORIZADO DOBLE CIEGO DESEMPEÑO DE DOS MATERIALES OBTURANTES EN BIOPULPECTOMÍAS DE MOLARES DECIDUALES: ESTUDIO CLÍNICO ALE. 2020;

\section{CITAR ESTE ARTICULO:}

Valarezo Bravo, T., \& Torres Villalta, M. (2020). Revisión bibliográfica del calen/zo como material obturador en pulpectomías. RECIAMUC, 4(3), 375-388. doi:10.26820/reciamuc/4.(3).julio.2020.375-388 